\title{
CS Research Square \\ Relationship Between Anatomical Characteristics and Personality Traits in Lipizzan Horses
}

\author{
Nataša Debeljak \\ University of Ljubljana \\ Aljaž Košmerlj \\ Jozef Stefan Institute \\ Jordi Altimiras \\ Linköping University \\ Manja Zupan Šemrov ( $\square$ manja.zupansemrov@bf.uni-lj.si ) \\ University of Ljubljana
}

\section{Research Article}

Keywords: equine, response, learning, fearfulness, handling, anatomy, hear rate

Posted Date: January 20th, 2022

DOl: https://doi.org/10.21203/rs.3.rs-1265483/v1

License: (9) (i) This work is licensed under a Creative Commons Attribution 4.0 International License. Read Full License 


\section{Abstract}

We tested 35 Lipizzan horses older than five years, ridden and healthy in three behavioural tests (handling, fearreaction, and learning ability test). Physiological (heart rate and heart rate variability) and anatomical measurements (120 head and body distances and angles) were collected to validate parameters that reliably inform on fear/exploration and learning ability in horses. Utilizing a standard clustering methodology on the behavioural data, we identified four general types of responses and categorised an individual as intermediate, low fearful, hard to handle or with low learning ability. We additionally analysed the head morphology following Tellington-Jones and Taylor recommendations and correlated the measurements with data from a horse personality questionnaire. Although allocation to a particular personality group was not associated with these two methods, these groups differed in six anatomical characteristics of head and body. Regardless of the group, our

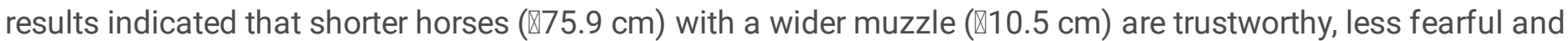
easier to handle and train. We also demonstrated that horses with stronger legs and a wider base of the head have a lower heart rate when exposed to the second trial of the handling test.

\section{Introduction}

Horse owners and caretakers frequently provide anecdotal evidence supporting the existence of family trends in behaviour and temperament, which are aspects of the personality of a horse. Although horse personality assessment protocols have been developed, progress on assessing their reliability and optimizing their use has been slow. Horse breeders rely on the ability to select a horse that is trustworthy, explorative, easy to handle, relaxed and that does not show fearful responses or panic and there is evidence that temperament traits can be used to select suitable training and weaning methods, choose or breed horses for police or therapeutic work, investigate underlying reasons for development of behavioural problems or assess how an unknown horse might react to a new or aversive situation or stimulus $(1,2,3,4)$.

Studies on horse personality typically rely on

only one or two methods and a multifactorial approach when looking at individual behaviour differences over time and in different contexts is lacking. Four different methods are used for personality assessment of horses: 1) questionnaire-based $(5), 2)$ behavioural tests $(6,7,8), 3)$ heart rate-based $(8,9)$ and 4$)$ grading by anatomical characteristics (10). The first two methods have already seen extensive use, while the other two methods are still under development, particularly the last method where there are very limited findings, focused mainly on horse's facial hair whorls $(7,10,11)$.

To our knowledge, the role of conformation (shape or structure of the horse) on personality has not been investigated. But horse conformation has been linked to biomechanics, and this in turn may affect personality characteristics $(12,13)$. Tellington-Jones and Taylor (12) concluded that an ideal thoroughbred with great athletic abilities should have head, neck, shoulders, back and croup of the same length. Any deviation in measurements, except for the croup, could lead to stiffness and pain which could cause unwillingness, unsoundness and resistance. Groesel et al. (13) showed that the length of the back muscle and consequently the length of the back affects horse movement.

An association between body characteristics and personality has been claimed for many species. The most excitable pigs and cattle have long slender bodies and fine bones (10) and more 
dominant chimpanzees have a larger frontal cortex (14). Holl et al. (15) found that pigs and cattle with

large bulging muscles often have calmer temperaments compared to lean animals with less muscle. In sheep, Hansen et al. (16) observed that lighter breeds had stronger flocking behaviour and larger flight zones when confronted with threatening stimuli. Krushinskii and Haigh (17) reported that slender, narrow-

bodied dogs had increased excitability and were more fearful compared to "athletic widebodied" dogs. McGreevy et al. (18) noted different behaviours that were linked with height, body weight or skull shape in dogs. One possible reason for the lack of literature on conformation scoring in horses, as mentioned by Back and Clayton (19), is that current methods are suboptimal, with subjectively defined traits and no adequate information on their relative weights. Although Tellington-Jones and Taylor (12) described a different number of characteristics of a horse's head and linked them to specific horse personality traits, they were not consistently defined in any objective way and its specific meaning was not validated.

To choose the behavioural tests in our study, we evaluated what riders, breeders or owners consider important in a horse. According to the questionnaire of Graf et al. (3), respondents assigned more importance to personalityrelated character and temperament traits than to performance traits. In another questionnaire-based study by AxelNilsson et al. (4), participants marked the trait 'ease to bring to new environments' as the most important. Our review of popular science resources indicated that confidence, cooperativity, and trainable traits are most wanted by horse trainers, breeders and riders. Other characteristics known to be of a great importance are fear of objects, sounds, and movements (20). The challenge can be even bigger for a horse, if these stimuli are combined: thus, the situation where a horse is faced with a moving unknown object that produces sound is considered highly challenging. With this in mind, we put together a battery of three behavioural tests: a handling test (21), a fear reaction test (22), and a learning/memory test labelled a target training test $(1,23)$. The chosen behavioural tests measure the personality traits of fearfulness, curiosity, ease of handling or willingness to cooperate, and also learning abilities and trainability.

To explore a comprehensive and non-invasive approach to robust phenotypic characterization in horses we used the Lipizzan horse as a model. We chose this breed as it is recognized as one of the oldest cultural breeds of horses in the world, but we still have little knowledge on how to identify a good riding, working, companion or therapeutic Lipizzan horse at an early age. To address this lack of information, in this multifactorial study, three main objectives were considered: 1) assign individual horses to response groups based on different behaviour patterns; 2) evaluate variation in anatomy of head and body and cardiovascular activity of all horses and within the response group; 3 ) to evaluate objectivity of the used methods and identify the ones that are easy to implement under practical conditions.

\section{Results}

\section{The relationship between anatomical and physiological measurements and horse behaviour}

To analyse the relationship between horse physiology and behaviour we decided on a robust approach of direct pairwise comparison with basic statistics. This decision was made because the dataset we are working with is small and we are thus very limited in the computations we make and the conclusions we can draw from the results. The coefficient of determination and the Pearson correlation coefficient were computed between anatomical measurements of the head and body and physiological measurements and its behaviour on the whole set of horses as well as within the four clusters. These values indicate the body measurements that seem the most related to the behaviour characteristics. High values of the coefficients in our results do not (and cannot) prove any causal link 
between the anatomical and behavioural measurement. These results only serve as weak indicators of possible connections between them. They are what we can draw from the limited experiments we have performed and should be interpreted accordingly with reservation. They can however serve as guides for further study and more experiments and collected data are needed for any more confident claims about these relationships.

There are too many pairs of measurements to include them all in the paper. For clarity we only show the pairs with the greatest values of the two coefficients, while others are presented in the Appendixes (Supplementary Table S1). We chose two threshold values for the coefficient of determination, using a threshold of 0.3 for coefficients related to the anatomical measurements that were found significant in all the horses and a coefficient of above 0.8 for the measurements significant in separate groups of horses to judge the coefficients in the clusters more harshly due to their smaller size.

Regardless of the group an individual horse was allocated to, four anatomical measurements were found to be correlated either with the max heart rate (HR) during the second trial in the HT or subordinated / distrustful behaviours observed in the FRT or locomotor activity (fast moving forward) performed in the HT (Table 1, Figure 1). These measures were (1) a cornet scope of front leg (FB12), explaining almost 36\% of variability of the max heart rate, (2) distance between the roots of the ears (FH01), explaining $32 \%$ of variability of the max heart rate, (3) chest length (FB20), explaining 35\% of the variability for behaviours in the FRT, and (4) distance between the superior parts of nostrils (HMP13), explaining $33 \%$ of the variability found for behaviours in the HT.

In the horses from the intermediate group (C1 horses) the inferior angle of the nostril (HMP95) explained 84\% of the time needed to successfully finish the first trial in the TTT (Table 1, Figure 1). If the angle was greater, the horse needed more time to successfully finish the trial. The length of a front leg (FB32) explained $82 \%$ of the variability in time spent standing still or/and moving backward in the HT. If a horse had longer legs, it spent less time in an inactive state. In the horses from the low ability to learn group (C2 horses), a cornet scope of front leg (FB12) explained $95 \%$ of variability in time spent jumping, trotting, galloping and/or moving nervously in the HT. The correlation was found to be negative, meaning that a horse with a larger scope spent less time performing locomotor activities. A half of a mouth length (FH19) was significantly correlated with two behaviours: an average time an individual horse needed to finish HT and standing still and/or moving backward in the HT, explaining $96 \%$ or $97 \%$ of their variability, respectively. Horses with a bigger mouth needed more time to finish the test and spent more time in an inactive state. The angle of outer edge of the ear (HMP81) explained 97\% of the variability in time the horse needed to finish the first part of the first trial in the TTT, with horses having a bigger angle of the ear needing more time to finish.

In the horses from the low fearful and hard to handle groups, the distance between the carpal joints of the forelegs (FB29) explained $84 \%$ of variability in time the horse needed to finish the second trial in the TTT. The correlation was found to be negative in the low fearful group while positive in the hard to handle group. Horses in the low fearful group having higher measurements needed more time while, on the contrary, the horses from hard to handle group needed less time to finish the second trial in the TTT.

Table 1. Anatomical measurements with only significant coefficient of determination for predicting behaviours, with top number presenting the coefficient of determination and the bold font number presenting the Pearson correlation coefficient. 


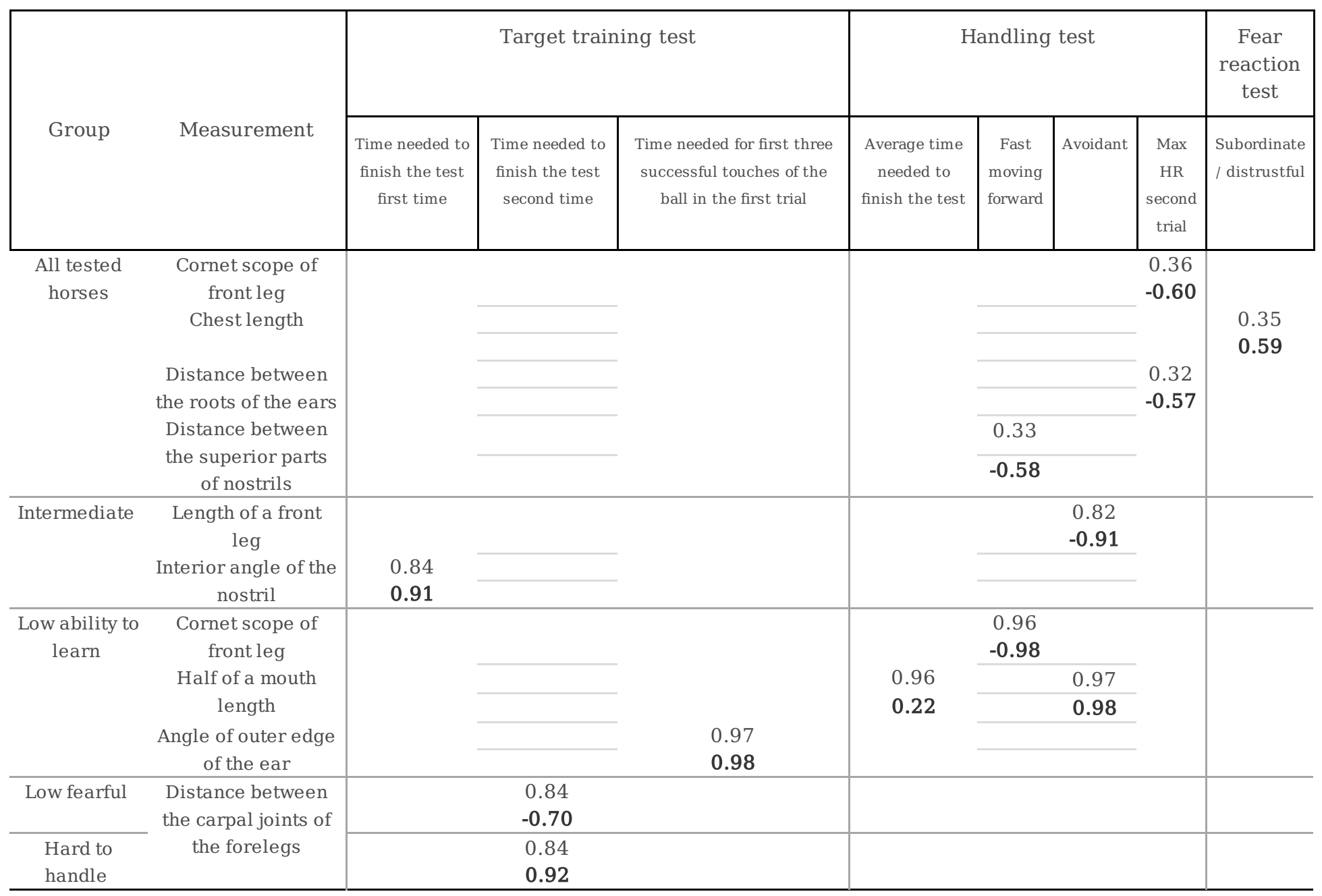

\section{Clustering based on behaviour-related variables}

Cluster analysis rendered four groups of horses based on the highest values of silhouette score of behavioural responses and between cluster distance values (Table 2). There were 10 horses (28.6\%) in the first group (C1 horses), 6 horses (17.1\%) in the second group (C2 horses), 8 horses (22.9\%) in the third group (C3 horses) and 11 horses (31.4\%) in the fourth group (C4 horses). Using four groups segmentation on behavioural responses, no sex differences (Chi-square test; $\mathrm{Chi}^{2}=3.13 ; \mathrm{P}=0.79$; data not shown) were found.

Five of the significant behavioural differences were found in the target training test (TTT), two in the handling test $(\mathrm{HT})$ and three in the fear reaction test (FRT). In the TTT, $\mathrm{C} 2$ horses needed the longest to successfully complete the second trial and longer in the first trial when compared to $\mathrm{C} 3$ and $\mathrm{C} 4$ horses. In the HT, C4 horses were less attentive / curious and more subordinated / distrustful than the $\mathrm{C} 2$ or C3 horses. In the FRT, C3 horses spent the longest time trotting, galloping, jumping and/or moving nervously and consequently they performed the least time standing still and/or moving backward and were less subordinated / distrustful than $\mathrm{C} 1$ horses. Based on these differences in the behavioural responses, the groups of horses were labelled as horses with low ability to learn (C2 horses), low fear horses (C3 horses), hard to handle horses (C4 horses) and horses which did not stand out in any of the tests (C1 horses). 
Note that this characterisation of the four groups is an interpretation of the differences in the behavioural variables. The clustering method and the statistics comparison only show that there is a division into subgroups which can be claimed to differ in their measurement values with statistical confidence. The characterisation of the differences is effectively expert opinion and not a direct result of statistical analysis.

\section{Comparison of the group segmentation using different assessment methods}

To test if Tellington-Jones and Taylor (TJ; 12) and horse personality questionnaire (HPQ) methods identify any differences in horse behaviour, we analysed if groups of horses with distinct behaviour can be formed using these methods' values alone. We have shown in the previous section that such a split of the horses in our dataset exists. The rationale is that if TJ and HPQ methods capture some information on horse behaviour then we should be able to identify groups with distinct behaviour by using the same clustering approach as before on the TJ and HPQ variables respectively. We ran the clustering algorithm on both sets of variables, clustering the horses into four groups both times. The results of the ANOVA test on the resulting groups are presented in Table 3 . For both methods, the differences between groups are much less significant than in our previous test. For only one behavioural feature (Fast moving forward) the groups split on HPQ variables show difference at the significance level of 0.1 . For most of the other groups the ANOVA test shows much less significant differences. These results suggest that TJ and HPQ methods do not capture any information useful for discerning horse behaviour. One might try to argue that the problem is in the clustering algorithm and that the information is just encoded in such away in the variables, that the algorithm is too weak to make sense of. Given the relatively simple nature of the TJ and HPQ variables this does not seem likely. Both methods are designed to draw clear indication of horse behaviour, not complex indicators which would need sophisticated processing to interpret.

Table 2. Calculated average values (AV), standard deviation (SD), F-values and P-values for four groups of horses (C1 - C4), derived from behavioural data in the behavioural tests. C1 - intermediate horses; C2 - low ability to learn horses; C3 - low fearful horses; C4 - hard to handle horses 


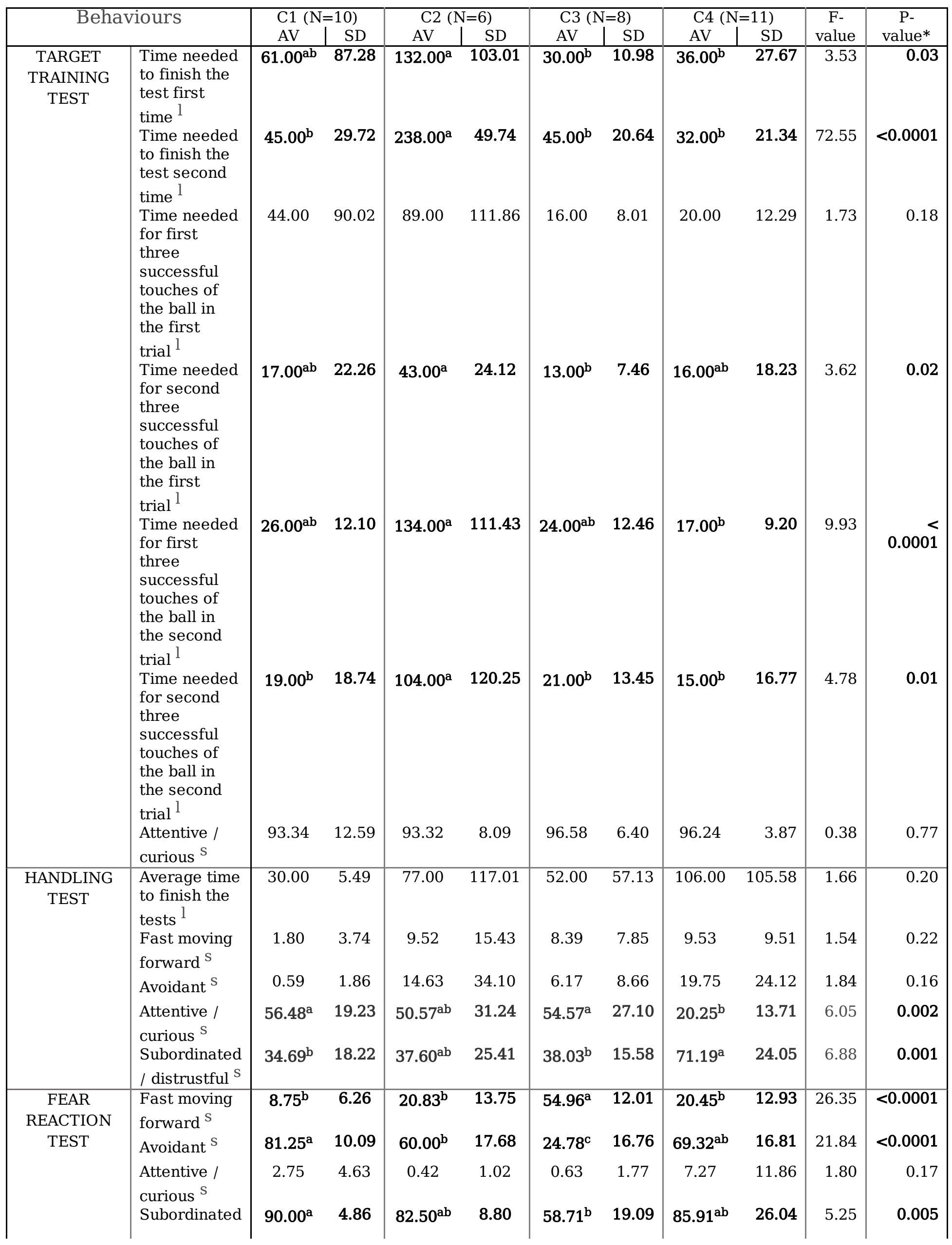


${ }^{1}$ Values represent latencies, measured in seconds (s),${ }^{s}$ Values represent percentage (\%) of the total testing time. *Pair-wise behavioural results of the horses with statistical significance at $0.05(\mathrm{p}<0.05 / 6)$ in bold.

Table 3. The ANOVA test for groups of horses that had comparable responses to three behavioural tests, for head characteristics based on Tellington-Jones and Taylor descriptions and for the questionnaire data.

\begin{tabular}{|c|c|c|c|c|c|}
\hline \multirow{2}{*}{\multicolumn{2}{|c|}{ Behaviours }} & \multicolumn{2}{|c|}{$\begin{array}{l}\text { Tellington-Jones and } \\
\text { Taylor method }\end{array}$} & \multicolumn{2}{|c|}{$\begin{array}{l}\text { Horse personality } \\
\text { questionnaire method }\end{array}$} \\
\hline & & F-value & P-value & F-value & P-value \\
\hline \multirow{8}{*}{$\begin{array}{l}\text { TARGET } \\
\text { TRAINING } \\
\text { TEST }\end{array}$} & Time needed to finish the test (for the) first time ${ }^{l}$ & 1.19 & 0.33 & 0.24 & 0.87 \\
\hline & Time needed to finish the test second time ${ }^{l}$ & 1.25 & 0.31 & 0.79 & 0.51 \\
\hline & $\begin{array}{l}\text { Time needed for first three successful touches of } \\
\text { the ball in the first trial }\end{array}$ & 1.40 & 0.26 & 0.66 & 0.58 \\
\hline & Time needed for second three successful touches & & & & \\
\hline & of the ball in the first trial ${ }^{l}$ & 1.28 & 0.30 & 1.26 & 0.31 \\
\hline & $\begin{array}{l}\text { Time needed for first three successful touches of } \\
\text { the ball in the second trial } \\
\text { Time needed for second three successful touches }\end{array}$ & 1.15 & 0.34 & 0.74 & 0.54 \\
\hline & of the ball in the second trial ${ }^{l}$ & 0.76 & 0.52 & 0.15 & 0.93 \\
\hline & Attentive / curious $\mathrm{s}$ & 0.86 & 0.47 & 0.33 & 0.80 \\
\hline \multirow{5}{*}{$\begin{array}{l}\text { HANDLING } \\
\text { TEST }\end{array}$} & Average time to finish the tests ${ }^{l}$ & 0.94 & 0.43 & 0.31 & 0.81 \\
\hline & Fast moving forward ${ }^{\mathrm{S}}$ & 0.24 & 0.87 & 1.27 & 0.30 \\
\hline & Avoidant $^{\mathrm{S}}$ & 1.46 & 0.24 & 0.41 & 0.75 \\
\hline & Attentive / curious $\mathrm{s}$ & 0.40 & 0.75 & 0.40 & 0.75 \\
\hline & Subordinated / distrustful ${ }^{\mathrm{S}}$ & 0.44 & 0.73 & 0.03 & 0.99 \\
\hline \multirow{4}{*}{$\begin{array}{c}\text { FEAR } \\
\text { REACTION } \\
\text { TEST }\end{array}$} & Fast moving forward ${ }^{\mathrm{s}}$ & 0.38 & 0.77 & 2.30 & 0.10 \\
\hline & Avoidant ${ }^{\mathrm{s}}$ & 0.16 & 0.92 & 2.04 & 0.13 \\
\hline & Attentive / curious ${ }^{\mathrm{S}}$ & 2.03 & 0.13 & 0.88 & 0.46 \\
\hline & Subordinated / distrustful $\mathrm{S}$ & 0.84 & 0.41 & 0.43 & 0.74 \\
\hline
\end{tabular}

${ }^{l}$ Values represent latencies, measured in seconds (s), s Values represent percentage (\%) of the total testing time

\section{Discussion}

In this horse study, we identified four general groups of mature Lipizzan horses when exposed to fearful and handling as well as learning situations. Using a standard clustering methodology on behaviour data we identified four groups which were shown to have statistically significant differences in measurements of their behaviour. Through expert interpretation of these differences, the groups were designated as "low fearful", "hard to handle", "with low learning ability" and an "intermediate group where horses did not stand out in their responses". A statistical comparison of behaviour and physiological measurements was also performed. The results suggest that the size of body and head may be a factor related to personality and cognitive skills, which to our knowledge has never been scientifically shown in an animal species. As the dataset is limited, further study is needed on more horses to confirm or disprove these relationships.

From behavioural observations, each individual was assigned to a particular cluster group associated with behaviour responses (including response latencies, limb movements, activities and expressions; Table 4). Our four 
distinctive clusters may suggest there was enough biological sensitivity to the contexts (24) but might also reflect different individual experience with humans (25), since horses were confronted with an unknown person during testing and handling. This factor may have affected horses' memories of human actions either positively or negatively (26). To date, the most frequently mentioned categorisation of animal responses to a challenging situation are reactive, proactive (farm animals: 27 ; horses: 4,28 ) or intermediate (farm animals: 29). After using a cluster analysis approach, our tests elicited four different categorized behavioural responses as C1, C2, C3 and C4 groups. Based on expert interpretation of the groups, group C1 combined intermediate horses, group C2 horses with a low learning ability, C3 low fear and C4 hard to handle horses, with the majority of horses being categorised as hard to handle, and having a low level of exploration and dominance attitude. The minority of horses was categorized as having a low learning ability (Table 2). This finding may not be surprising, knowing that breeding programs of Lipizzan horses have targeted fast learners.

Correlation analysis found nine characteristics of body $(n=4)$ and head $(n=5)$ to be indicative of behaviour and heart rate during test (Table 1, Figure 1). These results show some promise that, by using a larger sample size, a connection between physiological characteristics and the behaviour types could be confirmed. We provide initial evidence that the anecdotal beliefs of an association between personality traits on one hand and specific body and head measures as well as cardiovascular activity on the other hand exist. Although one could argue that age was confounding factor with age and body dimensions being related, the age criterion was breed related as a five-year-old Lipizzan horse is mature and fully-grown at this age and thus it does not change significantly over the following years (30).

While respecting the relative weakness of evidence available so far, we offer a possible interpretation of these differing characteristics. Out of the nine mentioned characteristics, four related to all the horses tested, two on the head (i.e., distances between the roots of the ears and between the superior parts of the nostrils) and two on the body (cornet scope of front leg and chest length). When the chest was longer, horses showed more subordinated / distrustful emotional reaction in the fear reaction test situation that may, according to its specifics (20), present most risk to riders and handlers of horses. This indicates that horse breeders may have difficulties building trustworthy relationships with horses with longer backs since trust is essential during daily handling routines (3) in order to prevent injuries of both rider and a horse (28). Knowing that in the fear reaction test we were not limiting the movements of a horse, or only when a horse chose to turn its back towards the handler, this observed mistrust may be linked to a higher level of fear (23). When distances between the roots of the ear and cornet scope of front leg were greater, heart rate decreased, however, in the second trial of the handling test only. This may result from a greater distance between the nostrils leading to the observed decrease in physical (locomotor) activity. Assuming that completing the handling test with lower activity is a sign of a greater stimulus control and ease to handle (31), our results imply that Lipizzan horses with wider heads and greater cornet scopes (i.e., strong legs) are calmer and more trustworthy, particularly after the second trial of testing.

To our knowledge this is the first evidence of a link between HR and anatomical characteristics of a horse's body and head in a human handling context. Previously, Górecka et al. (7) showed a lack of correlation between heart rate measures in a startle context and hair whorl height. Considering the results associated with all the horses, we suggest that the chest length (i.e., longer back) and distance between nostrils (i.e., wider muzzle) may be predictive of future level of trustworthiness in Lipizzan horses.

From a selection point of view (32) and in conjunction with our findings, Lipizzan horses having strong legs, a wide head and a short back would be preferred since they were found to be calmer and easier to train with a lower heart 
rate. We therefore suggest them to be safer and less time consuming to train. According to Grandin and Deesing (10), learning ability, memory, novelty seeking, activity level, fearfulness and sociability all show some degree of genetic influence. Therefore, for future studies with the objective of providing more robust breeding guidelines, we suggest to compare at the genome level clearly defined phenotypic groups which can provide the information about the underlying genetic variants.

The clustering into four behavioural groups was not associated with either the head characteristics described by TJ or results gathered by a HPQ that was filled-in by the horse trainers or owners. This means that after horses were clustered using these two methods, these groups did not show consistent differences in behaviour, implying that these methods do not have predictive value for traits such as fearfulness, handling and learning ability. Although TJ (12) provided some insights into the characteristics of a horse's head linked to specific horse personality traits, the use of this method needs profound experience with the visual conformation scoring. Furthermore, the description of personality traits is too broad to be precisely analysed and unreliably scored across assessors as such assessment may depend on how good an assessor knows a horse and on interpretation of an individual trait $(33,34)$.

Similarly, Seaman et al. (35) reported no relationship between the responses in their behavioural tests and the questionnaire ratings given by the farm team leader. To minimize the risk of subjectivity by the human respondents in the questionnaire, a larger number of respondents per horse and more complex statistical analysis are suggested to be used (36). In our study, unfortunately, we were able to collect only one questionnaire per horse. We also did not find any correlation between behavioural responses and hair swirls position, an association suggested previously $(7,11,37)$.

Although some attempts have been made in other species (pigs and cattle: $(10)$; dogs: $(17,18)$, including humans (38), all suggestions of an association between personality and anatomical characteristics are to date scientifically unproven. In this study, the pilot results show the first rigorous evaluation of a scientific association between behaviour that assigns an individual to a specific personality category, physiological response and anatomy in horses. We suggest that anatomical characteristics found in Lipizzan horses give a reliable and subjective measure to define personality traits and learning ability of an unknown horse. Our conclusions are based on a small number of animals, therefore it is important to conduct more work to ensure reliability of the method and to generalise the interpretation of the results to a wider cohort of Lipizzan horses. We believe that our study serves as a foundation for future research on physio-anatomical characteristics of horse personality in order to find individuals best suited for a specific use and thus improve handler safety and horse welfare.

\section{Materials And Methods}

\section{Ethical statement}

All procedures with animals were in accordance with the principals of the $3 \mathrm{Rs}$ and were performed according to the legislation on animal experimentation in Slovenia. The experimental protocols were approved by the animal-welfare body at the Department of Animal Science that is a member of the Ethical Committee of the Administration of the Republic of Slovenia for Food Safety, Veterinary Sector and Plant Protection (UVHVVR).

\section{Animals}


The study involved 35 Lipizzan horses ( $n=17$ mares, $n=1$ stallion, $n=17$ geldings) that originated from five horse facilities in Slovenia. The horses were five years old or older, they were ridden (trained to a saddle, performed changes in direction and speed under command by using classical, and/or traditional English style riding principles) and were healthy. All horses were kept in stables during the night and on pastures or paddocks during the day. Most horses had been purchased as yearlings, therefore we were not able to collect data on their early experience with humans, although it is believed that early formation of the foal-human relationship influences an animal's personality, learning ability and cognition (10) and thus can shape responses later in life.

\section{Data collection}

Physiological measures (heart rate (HR) and heart rate variability (HRV)) were first taken during rest while horses were stalled in an individual box, which was their familiar environment. They were loose in the box and without halters. These physiological measurements were repeated for five consecutive days. Behavioural tests always applied in the same following order; the HT, the TTT, and the FRT. During these tests, the horses' HR was also monitored. Next, we gathered anatomical measurements of head and body while the horse was on a flat surface. In addition, the HPQ was sent to the owners/trainers of individual horses.

\section{Behavioural tests}

To test the personality of a horse, three behaviour tests were conducted: HT, TTT and FRT. Tests were carried out consecutively in this order, and were repeated twice with two days between repetitions. Our behavioural tests were adapted from the descriptions published in previous studies (reactivity test or novel object test: Górecka et al. (7); handling test or response to a person: Seaman et al. (35); arena test: Seaman et al. (35); ridden work tests: (8); problem solving test: (23)).

Briefly, the behavioural tests were conducted inside a testing field (15 $\mathrm{m} \times 6 \mathrm{~m}$ ), which was located in the available enclosed area around a horse facility. In the HT, two identical open umbrellas $(85 \mathrm{~cm})$ were positioned $5 \mathrm{~m}$ apart so that they formed a passage through which the handler led an individual horse. Prior to the start of each test, horse was allowed 10-minute adaptation period that was followed by the beginning of the test after the beginning line was passed by horses' first front hoof and ended after the horse's last hind hoof touched the ground $5 \mathrm{~m}$ from the umbrellas. In the FRT, the handler positioned the horse $5 \mathrm{~m}$ from an assistant who held a whip (65 $\mathrm{cm}$ long) with an attached blue and white plastic bag $(40 \times 30 \mathrm{~cm})$. The assistant then waved it in line of his body and facing the horse, using a fast, smooth and firm movement of figure $\infty$ for 20 seconds. In the TTT, horses were expected to touch a yellow foam ball (10 cm diameter, positioned $10 \mathrm{~cm}$ from horses' muzzle) at the end of a stick (50 cm long) 6 times while standing one meter away from a handler. They had no prior training or experience of this object. For the first three successful touches, a horse received a carrot cube, while for second three touches (ball unchangingly moved left, right and back left from horses' muzzle while maintaining $10 \mathrm{~cm}$ distance between ball and muzzle) no reward was given. Videos from each of the behavioural tests were saved onto a computer and analysed according to a predetermined ethogram (Table 4) using VLC media player program. This final ethogram is a result of our pilot observations on 5 horses (39).

Table 4: Behaviours recorded during the behavioural tests and their definitions.

$\mathrm{F}_{\text {frequency; }}{ }^{\mathrm{D}}$ duration; $*$ McDonnell (2003) ^ Ransom and Cade (41). ${ }^{\mathrm{s}}$ Values represent percentage (\%) of the total testing time. TTT- target raining test; HT - handling test.

\section{Physiological measures}




\begin{tabular}{|c|c|c|}
\hline Category & Behavior & Definition \\
\hline & & Limb movements \\
\hline $\begin{array}{l}\text { Fast moving } \\
\text { forward }\end{array}$ & $\mathrm{D}_{\text {Trot* }}$ & $\begin{array}{l}\text { Movement forward in a two-beat gait, in which diagonally paired feet } \\
\text { touch and lift simultaneously. }\end{array}$ \\
\hline & $\mathrm{D}_{\text {Gallop* }}$ & Fast four beat gaits. \\
\hline & $\mathrm{D}_{\text {Jump* }}$ & $\begin{array}{l}\text { With mostly hind leg propulsion, moving forward with the forelegs leaving } \\
\text { the ground first followed by the hind legs. Jumping can be vertical to clear } \\
\text { high obstacles or broad to span ditches or small streams. }\end{array}$ \\
\hline & $\mathrm{D}_{\text {Nervous movements }}$ & $\begin{array}{l}\text { Any individual movement in each direction of any of the four legs that did } \\
\text { not have a pattern. }\end{array}$ \\
\hline Avoidant & $\mathrm{D}_{\text {Still }}$ & The horse has all four hooves on the ground and not moving any of them. \\
\hline & $\mathrm{D}_{\text {Backward }}$ & Movement backward in slower or faster four beat gaits. \\
\hline & & Expressions \\
\hline $\begin{array}{l}\text { Attentive / } \\
\text { curious }\end{array}$ & $\mathrm{D}_{\text {Alert / attentive* }}$ & $\begin{array}{l}\text { Rigid stance with the neck elevated and the head oriented toward the } \\
\text { object or animal of focus. The ears are held stiffly upright and forward, } \\
\text { and the nostrils may be slightly dilated. }\end{array}$ \\
\hline & $\mathrm{D}_{\text {Curious* }}$ & $\begin{array}{l}\text { Stretched neck with movement, eyes and ears faced towards object of } \\
\text { interest. Base of the tail is raised above back line, wrinkled lips and } \\
\text { movements of nostrils can be seen when sniffing the object. }\end{array}$ \\
\hline $\begin{array}{l}\text { Subordinated } \\
\text { / distrustful }\end{array}$ & $\mathrm{D}_{\text {Subordinate }^{\wedge}}$ & $\begin{array}{l}\text { Head is low with ears hanging freely at the side of the head. Eyes are } \\
\text { open tail is inactive. }\end{array}$ \\
\hline & $\mathrm{D}_{\text {Distrustful* }}$ & $\begin{array}{l}\text { Head is high with tense neck and ears moving backward and forward. } \\
\text { Focus of the head and eyes varies from the point of interest and away } \\
\text { from it. Tail is inactive while horse can balk. }\end{array}$ \\
\hline & & Latencies \\
\hline $\begin{array}{l}\text { Finish } \\
\text { testing }\end{array}$ & $\begin{array}{l}\text { Time needed to finish the test } \\
\text { first and also second time in } \\
\text { HT }\end{array}$ & $\begin{array}{l}\text { The time when the horse's first front leg crossed beginning line of the } \\
\text { test was recorded and time when its last hind leg crossed the end } \\
\text { line. The duration presented time needed for horse to finish test. }\end{array}$ \\
\hline & $\begin{array}{l}\text { Time needed to finish the test } \\
\text { first and also second time in } \\
\text { TTT }\end{array}$ & $\begin{array}{l}\text { The time of the first touch and the last, } 6^{\text {th }} \text { touch of the ball was } \\
\text { recorded. The duration presented time needed for horse to finish } \\
\text { test. }\end{array}$ \\
\hline $\begin{array}{l}\text { Touching a } \\
\text { ball }\end{array}$ & $\begin{array}{l}\text { Time needed for first three } \\
\text { successful touches of the ball } \\
\text { in the first and also second } \\
\text { trial }\end{array}$ & $\begin{array}{l}\text { The time of the first and third touch of the ball was recorded. The } \\
\text { duration presented time needed for horse to partially finish test. }\end{array}$ \\
\hline & $\begin{array}{l}\text { Time needed for second three } \\
\text { successful touches of the ball } \\
\text { in the first and also second } \\
\text { trial }\end{array}$ & $\begin{array}{l}\text { The time of the fourth and sixth consecutive touch of the ball was } \\
\text { recorded. The duration presented time needed for horse to partially } \\
\text { finish test. }\end{array}$ \\
\hline
\end{tabular}

$\mathrm{HR}(\mathrm{V})$ during rest and during behavioural tests were recorded using Equine $\mathrm{H} 7$ heart rate sensor electrode base set and a receiver Polar V800 heart rate monitor (Helsinki, Finland). Contact electrodes were attached to a non-standard elastic belt, made for the purpose, and electrodes were placed to correct positions on a horse girth area. The contact between the rubber electrode areas and the horse's skin was optimized by using contact gel on the electrode areas. We placed a piece of furnishing foam beneath the electrodes and the elastic belt. Prior to testing, we let the horses get used to an elastic belt for 10 minutes. The resting values HR and HRV were recorded for the duration of about $60 \mathrm{~min}$ (from $45 \mathrm{~min}$ to $90 \mathrm{~min}$ ). The measurements were taken between 5:30 a.m. and 12 a.m., before the horses started with work or training, or from 6 p.m. to 8 p.m. after the horses went to rest. While measuring basal HR, owners and personnel were asked not to enter the stable to ensure a calm environment for the horses. We also asked owners of the horses to train their horses with fairly easy training sessions during the five days when the measurements were taken, as a hard training session the previous day can cause elevated heart rate at rest (42). The analysis of HR data from behavioural tests was made in the Polar Flow app, where we recorded the highest HR 
measurement. Basal HR data recordings were analysed in program Kubios HRV, where the most representative sample (i.e. consistent RR fluctuation during 5-day recordings; not standing out with an increase/decrease) of 14 minutes within one-hour recordings was analysed while artifact correction was set to medium and frequency bands were defined as very low frequency from 0 to $0.04 \mathrm{~Hz}$, low frequency from 0.04 to 0.13 and high frequency from 0.13 to $0.4 \mathrm{~Hz}$.

Body temperature was measured rectally with a digital thermometer after HR measurements, between 5:40 a.m. and 1 p.m. If the body temperature exceeded $39^{\circ} \mathrm{C}$, that horse was not included in the study on that day.

\section{Anatomical measurements}

Anatomical measurements were collected using three different approaches. First, according to the instructions given by Tellington-Jones and Taylor (12), we took a set of head pictures (resolution: 300 of pixels per inch) with camera Nikon D90 (12.3 - megapixel digital single-lens reflex camera) of each horse where the horse's front and left head profile was visible. Interpretation of pictures was done by following descriptions from the book of TellingtonJones and Taylor (12). Second, we additionally obtained a photo of the front profile by the same procedure as described above, with an addition of a ruler that consisted of $1 \mathrm{~cm} \times 1 \mathrm{~cm}$ square blocks $(2 \mathrm{~cm} \times 5 \mathrm{~cm}$, printed on self-adhesive white paper), that was attached to the front view of the horse's head, on the line of a lower end of the facial crest (Figure 2). Pictures from this approach were used to measure distances on the horse's head using a tpsDig232 program and CoordGen8 software. In total, 88 distances and angles extracted with the CoordGen8 program were converted to $\mathrm{cm}$ (Figure 2). Final, head anatomical characteristics were measured with a sartorial meter (Figure 3). In total, 19 head measurements were gathered on the horses' left or front sides of the head, and two head scope measurements. In addition to head measurements, the sartorial meter (a $2.5 \mathrm{~m}$ bendable meter with metric units) was used to collect 32 body measurements on the horses' left or front sides of the body (with the exception of scopes) (Figure 3). Measurements with a sartorial meter were done twice in two days.

\section{Questionnaire for horse trainers/owners}

Horse owners or trainers received a paper-and-pencil HPQ, adapted from Lloyd et al. (43) (Supplementary Table S2) that consisted of a list of 30 adjectives with a number scale from one to seven. The HPQ was filled out by marking the appropriate number based on a list of adjective definitions. The value of one meant complete absence of a specific behaviour, the value of seven meant full expression of it, while number four represented an average value.

\section{Statistical analysis}

To reveal individual differences in behavioural characteristics of the horses, data from behavioural tests were used for segmentation of the horses into groups using standard clustering methodology. The K-means algorithm was applied and Euclidean distance (computed by the Pythagorean formula) was used as distance measure. We used the implementation that is part of the Orange software package (version 2.7 ). To assess quality of the segmentation of horses into groups, the silhouette score and between cluster distance was computed. In order to identify the characteristics in which differences were statistically significant between the clusters, we used the standard Student T-test for the analysis of clustering into two groups and the ANOVA test for clustering into four groups. To gain further insight into the differences between clusters we used the Bonferroni correction for the pairwise T-tests. Next, we divided all of the horses into 4 groups based on the Tellington-Jones and Taylor values

Page $13 / 21$ 
and HPQ values using the same k-means methodology. Having identified which horses belonged to which groups in the next step, used Pearson's chi-squared test, we investigated if those groups differed according to behavioural test results. The results did not show a dependence between the clusters, which meant the groups are different. Furthermore, we compared the groups using the ANOVA test on the behavioural characteristics of the horses.

Having established the 4 characteristically distinct groupings of horses based on behaviour, we tested the predictive power of anatomical characteristics for classification into these groups. We also computed the coefficient of determination (R2) and Pearson correlation coefficient between the anatomical, physiological and behavioural characteristics and HR responses in behavioural tests for all the horses and for each of the groups separately in order to directly test the relations between the two types of measurements. The two coefficients indicate the predictive value of each individual anatomical measurement for each individual behavioural characteristic independently. This gives a more fine-grained and robust indication of the relations, which are independent of modelling technique and clustering.

\section{Declarations}

\section{Acknowledgements}

The authors would like to thank to the personnel at the horse facilities that kindly provided the access to their horses.

\section{Author Contributions}

N. D.: Conceptualization, Methodology, Formal analysis, Investigation, Prepared figures and tables. A. K.: Statistical analysis, writing - statistical section, review \& editing. J. A.: Methodology of physiological measures, Review \&

Editing. M. Z. Š: Conceptualization, Methodology, Visualization, Resources, Writing - original draft, Supervision.

\section{Data Availability}

The datasets gathered during the current study are available on request from the corresponding author.

Competing financial interests: The authors declare no competing financial and non-financial interests.

\section{References}

1. Hausberger, M., Bruderer, C., LeScolan, N. \& Pierre, J. S. Interplay Between Environmental and Genetic Factors in Temperament/Personality Traits in Horses (Equus caballus). J. Comp. Psychol.70, 227-

237; https://doi.org/10.1037/0735-7036.118.4.434 (2004).

2. Olsson, K. A. Review of methods used to measure temperamental characteristics in horses. Preprint at https://stud.epsilon.slu.se/1575/1/olsson_k_100706.pdf (2010).

3. Graf, P., König von Borstel, U. \& Gauly, M. Importance of personality traits in horses to breeders and riders. J. Vet. Behav.8, 316-325; https://doi.org/10.1016/j.jveb.2013.05.006 (2013).

4. Axel-Nilsson, M., Peetz-Nielsen, P., Visser, E. K., Nyman, S. \& Blokhuis, H. J. Perceived relevance of selected behavioural traits in horses - A survey conducted in Sweden. Acta Agr. Scand. A-An.65, 23-

32; https://doi.org/10.1080/09064702.2015.1047791 (2015).

Page $14 / 21$ 
5. Momozawa, Y., Kusunose, R., Kikusui, T., Takeuchi, Y. \& Mori, Y. Assessment of equine temperament questionnaire by comparing factor structure between two separate surveys. Appl. Anim. Behav. Sci.92, 7784; https://doi.org/10.1016/j.applanim.2004.11.006 (2005).

6. Rietmann, T. R. et al. Assessment of mental stress in warmblood horses: Heart rate variability in comparison to heart rate and selected behavioural parameters. Appl. Anim. Behav. Sci.88, 121136; https://doi.org/10.1016/j.applanim.2004.02.016 (2004).

7. Górecka, A., Golonka, M., Chruszczewski, M. \& Jezierski, T. A note on behaviour and heart rate in horses differing in facial hair whorl. Appl. Anim. Behav. Sci.105, 244-248; https://doi.org/10.1016/j.applanim.2006.05.013 (2007).

8. Munsters, C. C. B. M., Visser, K. E. K., van den Broek J. \& Sloet van Oldruitenborgh-Oosterbaan, M. M. The influence of challenging objects and horse-rider matching on heart rate, heart rate variability and behavioural score in riding horses. Vet. J.192, 75-80; https://doi.org/10.1016/j.tvjl.2011.04.011 (2012).

9. Stucke, D., Große Ruse, M. \& Lebelt, D. Measuring heart rate variability in horses to investigate the autonomic nervous system activity - Pros and cons of different methods. Appl. Anim. Behav. Sci.166, 110; https://doi.org/10.1016/j.applanim.2015.02.007 (2015).

10. Grandin, T. \& Deesing, M. J. Genetics and the Behavior of Domestic Animals (2nd ed.) 488 p. (London: Academic Press, 2014).

11. Sereda, N. H., Kellogg, T., Hoagland, T. \& Nadeau, J. Association between whorls and personality in horses. J. Equine Vet. Sci.35, 428; https://doi.org/10.1016/j.jevs.2015.03.116 (2015).

12. Tellington-Jones, L. \& Taylor, S. Getting in TTouch with your horse: how to assess and influence personality, potential, and performance 198 p. (Trafalgar Square Books, 2009).

13. Groesel, M., Zsoldos, R. R., Kotschwar, A., Gfoehler, M. \& Peham, C. A preliminary model study of the equine back including activity of longissimus dorsi muscle. Equine Vet. J.42, 401-406; https://doi.org/10.1111/j.20423306.2010.00282.x (2010).

14. Latzman, R. D., Hecht, L. K., Freeman, H. D., Schapiro, S. J. \& Hopkins, W. D. Neuroanatomical correlates of personality in chimpanzees (Pan troglodytes): Associations between personality and frontal cortex. Neurolmage.123, 63-71; https://doi.org/10.1016/j.neuroimage.2015.08.041 (2015).

15. Holl, J. W., Rohrer, G. A. \& Brown-Brandl, T. M. Estimates of genetic parameters among scale activity scores, growth, and fatness in pigs. J. Anim. Sci.88, 455-459; https://doi.org/10.2527/jas.2008-1559 (2010).

16. Hansen I., Christiansen F., Hansen H.S., Braastad B., \& Bakken, M. 2001. Variation in behavioural responses of ewes towards predator-related stimuli. Appl. Anim. Behav. Sci.70, 227-237; https://doi.org/10.1016/s01681591(00)00155-6 (2001).

17. Krushinskii, L.V. \& Haigh, B. Animal behavior: Its normal and abnormal development 261 p. (Consultants Bureau, 1961).

18. McGreevy, P.D. et al. Dog Behavior Co-Varies with Height, Bodyweight and Skull Shape. PLoS One. 8(12): e80529; https://doi.org/10.1371/journal.pone.0080529 (2013). 
19. Back, W. \& Clayton, H. M. Equine Locomotion 528 p. (Saunders Elsevier, 2012).

20. McLean, A. N. \& McGreevy, P. D. Horse-training techniques that may defy the principles of learning theory and compromise welfare. J. Vet. Behav.5, 187-195; https://doi.org/10.1016/j.jveb.2010.04.002 (2010).

21. Visser, E. K. et al. Quantifying aspects of young horses' temperament: consistency of behavioural variables. Appl. Anim. Behav. Sci. 74, 241-258; https://doi.org/10.1016/S0168-1591(01)00177-0 (2001).

22. Brunberg, E., Gille, S., Mikko, S. \& Lindgren, G. Icelandic horses with the Silver coat colour show altered behaviour in a fear reaction test. Appl. Anim. Behav. Sci.146, 72-

78; https://doi.org/10.1016/j.applanim.2013.04.005 (2013).

23. Le Scolan, N., Hausberger, M. \& Wolff, A. Stability over situations in temperamental traits of horses as revealed by experimental and scoring approaches. Behav. Processes.41, 257-266; https://doi.org/10.1016/S03766357(97)00052-1 (1997).

24. Langenhof, M. R., \& Komdeur, J. Why and how the early-life environment affects development of coping behaviours. Behav. Ecol. Sociobiol.72, 34; https://doi.org/10.1007/s00265-018-2452-3 (2018).

25. Fureix, C. et al. A preliminary study of the effects of handling type on horses' emotional reactivity and the human-horse relationship. Behav. Processes.82, 202-10; https://doi.org/10.1016/j.beproc.2009.06.012 (2009).

26. Henry, S., Richard-Yris, M-A. \& Hausberger, M. Influence of various early human-foal interferences on subsequent human-foal relationship. Dev. Psychobiol.48, 712-8; https://doi.org/10.1002/dev.20189 (2006).

27. Forkman, B., Boissy, A., Meunier-Salaün, M. C., Canali, E. \& Jones, R. B. A critical review of fear tests used on cattle, pigs, sheep, poultry and horses. Physiol. Behav.92, 340-374; https://doi.org/10.1016/j.physbeh.2007.03.016 (2007).

28. Budzyńska, M. Stress Reactivity and Coping in Horse Adaptation to Environment. J. Equine Vet. Sci.34, 935941; https://doi.org/10.1016/j.jevs.2014.05.010 (2014).

29. Finkemeier, M.-A. et al. Assessment of personality types in Nigerian dwarf goats (Capra hircus) and crosscontext correlations to behavioural and physiological responses. Appl. Anim. Behav. Sci.217, 28-

35; https://doi.org/10.1016/j.applanim.2019.05.004 (2019).

30. Bennett, D. Timing and rate of skeletal maturation in horses. Preprint at http://www.equinestudies.org/ranger_2008/ranger_piece_2008_pdf1.pdf (2008).

31. McGreevy, P. D. P. \& McLean, A. N. Punishment in horse-training and the concept of ethical equitation. J. Vet. Behav. Clin. Appl. Res.4, 193-197; https://doi.org/10.1016/J.JVEB.2008.08.001 (2009).

32. Rus, J. Rejski program za pasmo lipicanski konj. Preprint at https://www.lipica.org/si/stable/kobilarna/rejskiprogram (2010).

33. Gosling, S.D. \& Vazire, S. Are we barking up the right tree? Evaluating a comparative approach to personality. J. Res. Pers.36, 607-614; 
https://doi.org/10.1016/S0092-6566(02)00511-1 (2002).

34. Morris, P.H., Gale, A. \& Duffy, K. Can judges agree on the personality of horses? Pers. Individ. Differ.33, 6781; https://doi.org/10.1016/S0191-8869(01)00136-2 (2002).

35. Seaman, S. C., Davidson, H. P. B. \& Waran, N. K. How reliable is temperament assessment in the domestic horse (Equus caballus)? Appl. Anim. Behav. Sci. 78, 175-191; https://doi.org/10.1016/S0168-1591(02)00095-3 (2002).

36. Momozawa, Y. et al. Assessment of equine temperament by a questionnaire survey to caretakers and evaluation of its reliability by simultaneous behavior test. Appl. Anim. Behav. Sci. 84, 127-138; https://doi.org/10.1016/j.applanim.2003.08.001 (2003).

37. Murphy, J. \& Arkins, S. Facial hair whorls (trichoglyphs) and the incidence of motor laterality in the horse. Behav. Processes. 79, 7-12; https://doi.org/10.1016/j.beproc.2008.03.006 (2008).

38. Walker, R.N. \& Tanner, J. M. Prediction of adult Sheldon somatotypes I and II from ratings and measurements at childhood ages.Ann. Hum. Biol.7, 213-224; https://doi.org/10.1080/03014468000004261 (1980).

39. Debeljak, N. \& Zupan, M. Evaluation of horse personality based on constitutional characteristics. Acta Agric. Slov. 104, 33-44; http://dx.doi.org/10.14720/aas.2014.104.1.4 (2014).

40. McDonnell, S. A. practical field guide to horse behavior: The Equid ethogram 375 p. (Eclipse Press, 2003).

41. Ransom, J. I. \& Cade, B. S. Quantifying equid behavior- A research ethogram for free-roaming feral horses. Preprint at https://doi.org/10.3133/tm2A9 (2009).

42. Heipertz-Hengst, C. Equine Sport with Feeling and Know How. Preprint at https://ug1lib.org/book/2551280/2e087d (2002).

43. Lloyd, A. S., Martin, J. E., Bornett-Gauci, H. L. I. \& Wilkinson, R. G. Evaluation of a novel method of horse personality assessment: Rater-agreement and links to behaviour. Appl. Anim. Behav. Sci. 105, 205222; https://doi.org/10.1016/j.applanim.2006.05.017 (2007).

\section{Figures}



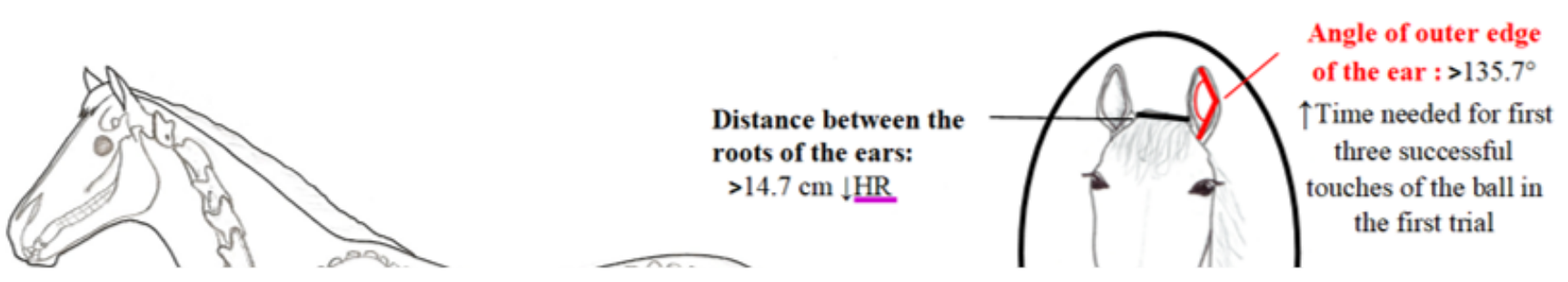

\section{Figure 1}

Anatomical measurements with only coefficient of determination for predicting behaviours and heart rate. Black line - all horses, green line - intermediate group, red line - low ability to learn group, blue line - low fearful (C3) and hard to handle (C4), purple line - relates to heart rate. $\downarrow \uparrow$ - relationship between measures and behaviours or heart rate if the anatomical measurement increases. 


\begin{tabular}{|r|r|r|}
\hline \multicolumn{3}{|c|}{ Angle measurements } \\
\hline First point & $\begin{array}{c}\text { Second } \\
\text { point }\end{array}$ & $\begin{array}{c}\text { Third } \\
\text { point }\end{array}$ \\
\hline 5 & 8 & 10 \\
\hline 8 & 9 & 10 \\
\hline 8 & 6 & 5 \\
\hline 8 & 5 & 10 \\
\hline 5 & 10 & 9 \\
\hline 4 & 1 & 31 \\
\hline 1 & 32 & 31 \\
\hline 1 & 3 & 4 \\
\hline 1 & 4 & 31 \\
\hline 3 & 4 & 31 \\
\hline 18 & 16 & 19 \\
\hline 18 & 17 & 19 \\
\hline 16 & 19 & 17 \\
\hline 16 & 18 & 17 \\
\hline 24 & 23 & 25 \\
\hline 24 & 22 & 25 \\
\hline 23 & 25 & 22 \\
\hline 23 & 24 & 22 \\
\hline 24 & 23 & 25 \\
\hline & & \\
\hline
\end{tabular}

\begin{tabular}{|r|r|r|r|r|r|}
\hline \multicolumn{7}{|c|}{ Linear measurements } \\
\hline First point & $\begin{array}{c}\text { Second } \\
\text { point }\end{array}$ & First point & $\begin{array}{c}\text { Second } \\
\text { point }\end{array}$ & First point & $\begin{array}{c}\text { Second } \\
\text { point }\end{array}$ \\
\hline 1 & 8 & 4 & 35 & 23 & 22 \\
\hline 2 & 7 & 31 & 35 & 16 & 17 \\
\hline 3 & 6 & 37 & 35 & 23 & 21 \\
\hline 4 & 5 & 30 & 35 & 22 & 21 \\
\hline 32 & 9 & 29 & 35 & 16 & 20 \\
\hline 31 & 10 & 5 & 36 & 17 & 20 \\
\hline 37 & 38 & 10 & 36 & 23 & 25 \\
\hline 30 & 11 & 38 & 36 & 16 & 19 \\
\hline 29 & 12 & 11 & 36 & 25 & 21 \\
\hline 28 & 13 & 12 & 36 & 19 & 20 \\
\hline 27 & 14 & 1 & 31 & 1 & 32 \\
\hline 26 & 15 & 1 & 4 & 8 & 9 \\
\hline 23 & 16 & 8 & 5 & 31 & 32 \\
\hline 24 & 18 & 8 & 10 & 9 & 10 \\
\hline 25 & 19 & 4 & 21 & 3 & 31 \\
\hline 22 & 17 & 5 & 20 & 6 & 10 \\
\hline 25 & 24 & 4 & 27 & 3 & 32 \\
\hline 18 & 19 & 5 & 14 & 6 & 9 \\
\hline 22 & 17 & 28 & 26 & 4 & 31 \\
\hline 21 & 20 & 13 & 15 & 5 & 10 \\
\hline & & & & & \\
\hline
\end{tabular}

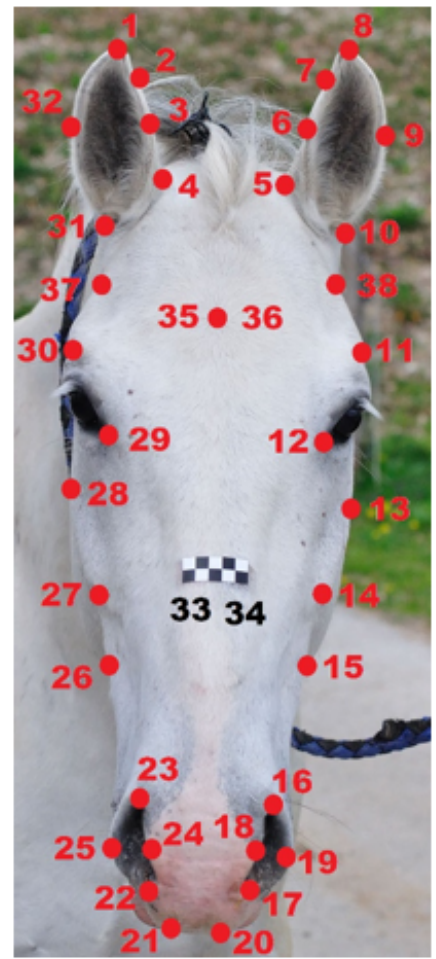

Figure 2.

\section{Figure 2}

Detailed description of measurements, extracted from the CoordGen8 computer program. Picture of the horse front head profile on the right represents how landmarks were positioned on the horse's head picture. Each landmark had an individual number that was consistent throughout all 35 horse pictures. Black numbers 33 and 34 were markers for unit of $1 \mathrm{~cm}$ (distance between them was $1 \mathrm{~cm}$ ). Table on the left represents measurements that were extracted from landmarks. Angle measurements represent angles, measured between 3 landmark points (first point, second point and third point) marked on the horse's head profile picture on the right, while linear measurements were actual distances between two landmark points (first point and second point) marked on the horse's head profile picture on the right. 


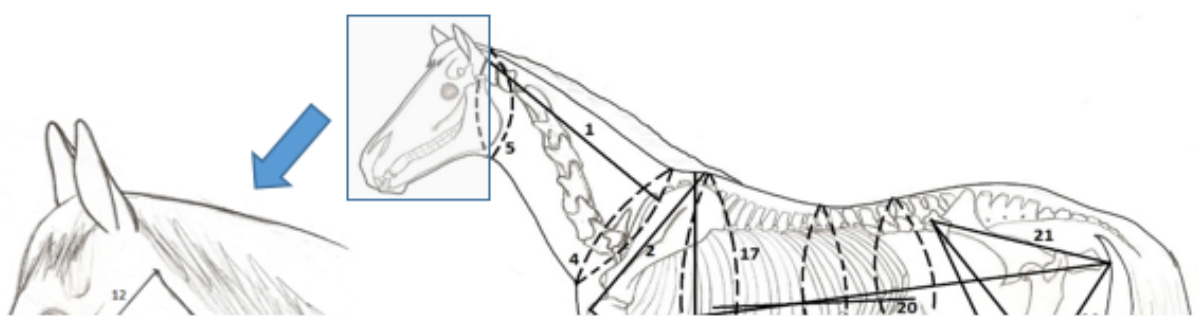

\section{Figure 3}

Detailed description of measurements, measured on the horse body and head. The horse body drawing represents important skeletal structures that were used during measurement as a reference point and we were able to locate them by using a palpating technique. The head drawing shows major anatomical characteristics of the horse's head that were also used as reference points to ensure comparable measurements between different horses.

\section{Supplementary Files}

This is a list of supplementary files associated with this preprint. Click to download. 
- SupplementaryTableS1.xlsx

- SupplementaryTableS2.pdf 